\title{
Total Synthesis of Jerangolid D
}

\author{
Jiří Pospíšil and István E. Markó* \\ Université catholique de Louvain, Département de Chimie, Bâtiment Lavoisier, \\ Place Louis Pasteur 1, B-1348 Louvain-la-Neuve, Belgium \\ marko@chim.ucl.ac.be
}

\section{Table of contents}

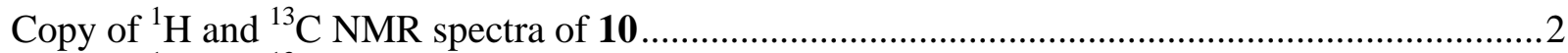

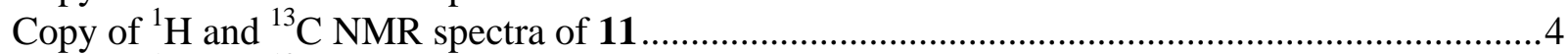

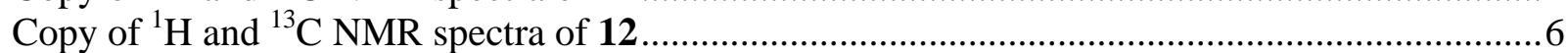

Copy of ${ }^{1} \mathrm{H}$ and ${ }^{13} \mathrm{C}$ NMR spectra of 6

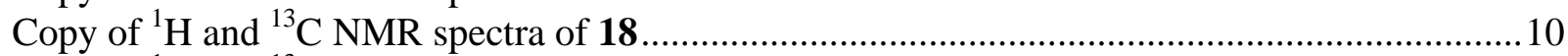

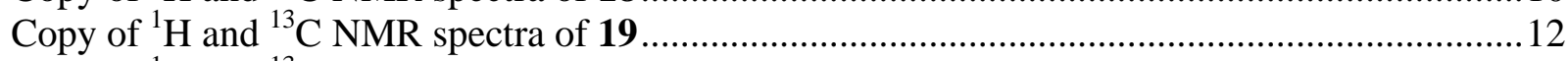

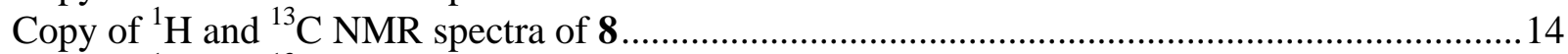

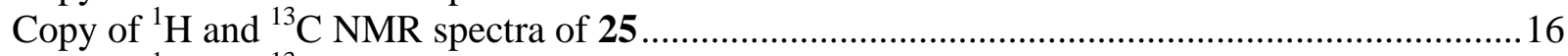

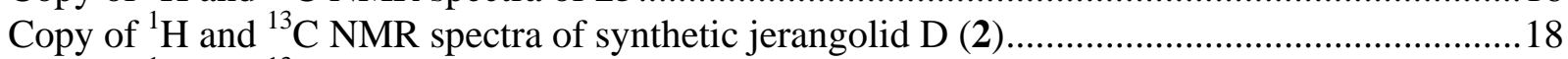

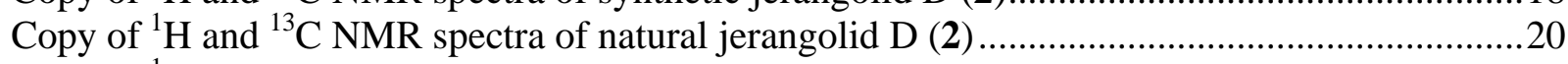

Copy of ${ }^{1} \mathrm{H}$ NMR spectra of commixed natural and synthetic jerangolid D (2) ...........................23 


\section{Copy of ${ }^{1} \mathrm{H}$ and ${ }^{13} \mathrm{C}$ NMR spectra of 10}

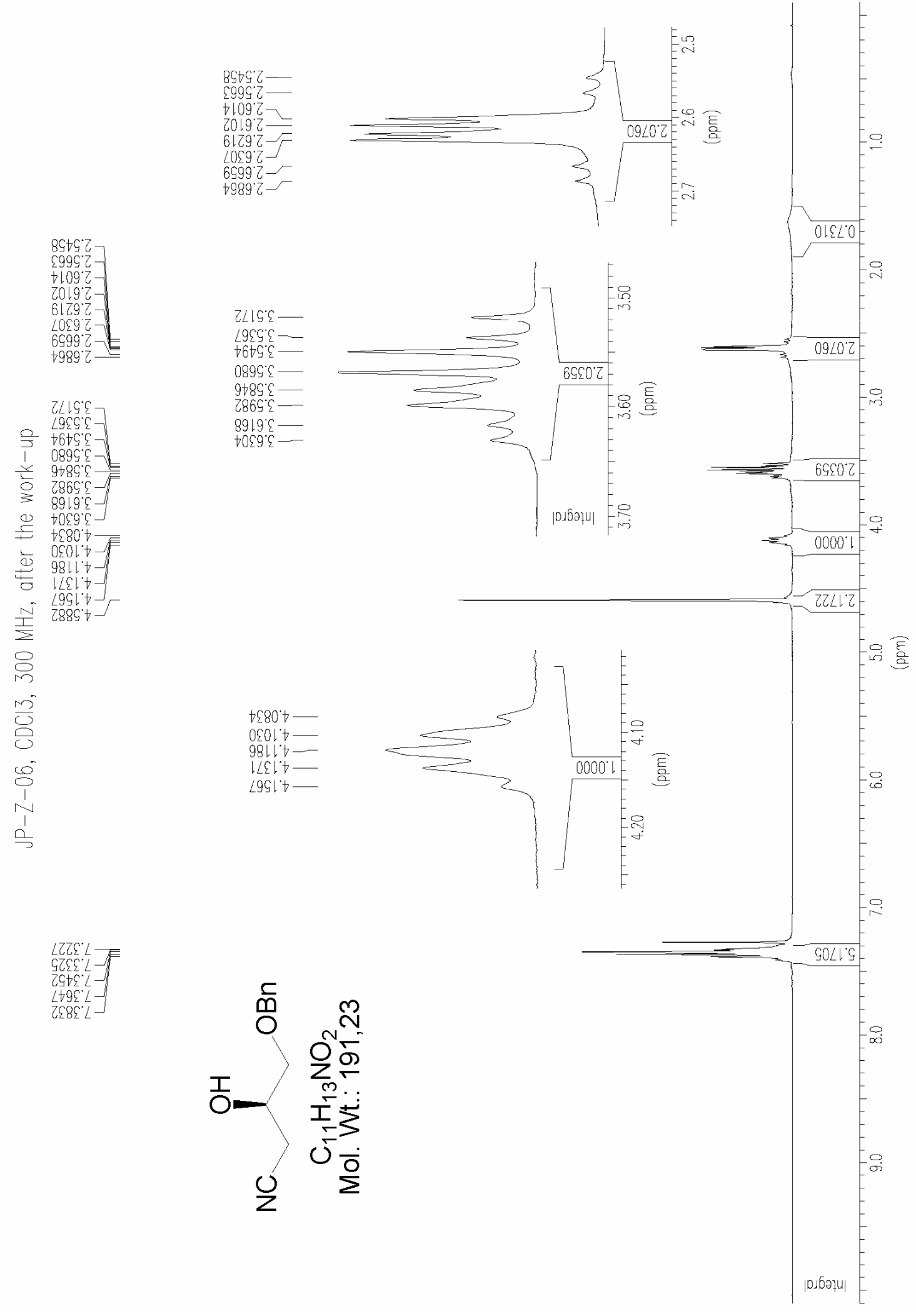




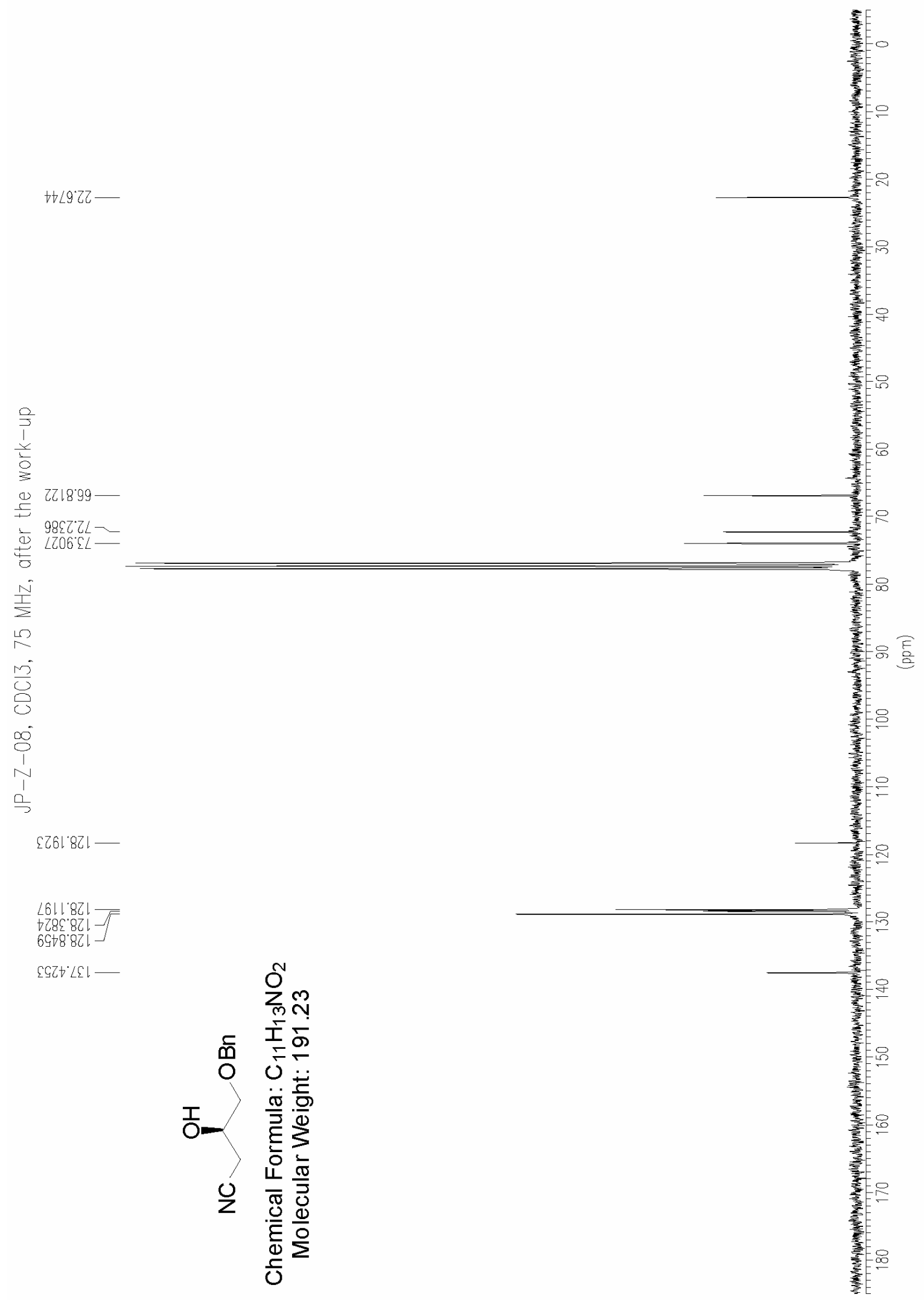




\section{Copy of ${ }^{1} \mathrm{H}$ and ${ }^{13} \mathrm{C}$ NMR spectra of 11}

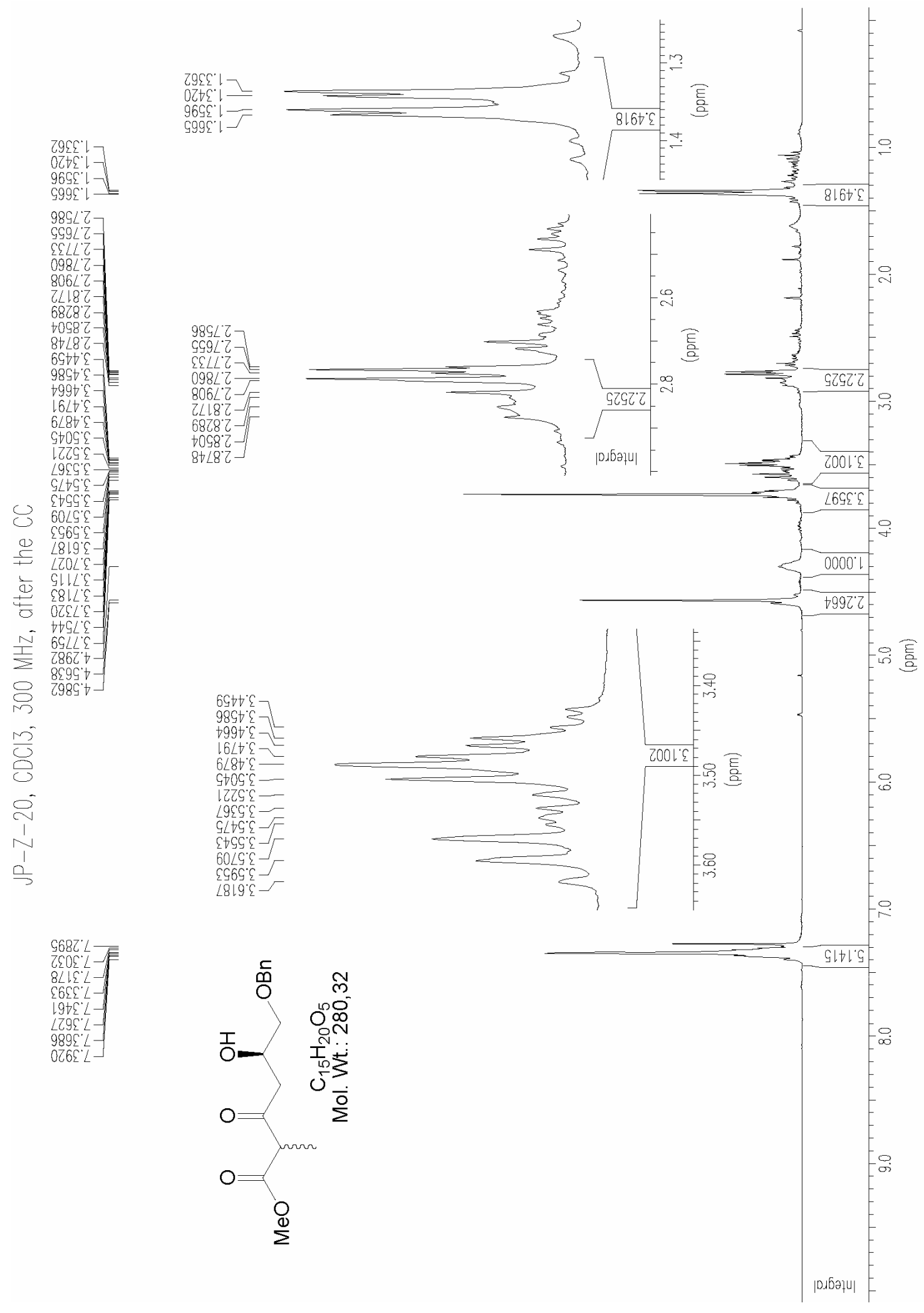




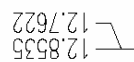

$9 \angle 98^{\circ}+7$
$9266^{\circ}+7$

$9122 \mathrm{ZS}$

768259
$686+59$

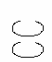

$\stackrel{\square}{\rightleftharpoons} 981699$

¿ 89225

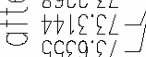

$\frac{N}{\equiv}$

10

$\frac{N}{0}$

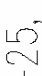

$N$

$\stackrel{\circ}{2}$

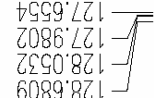

56.10851-

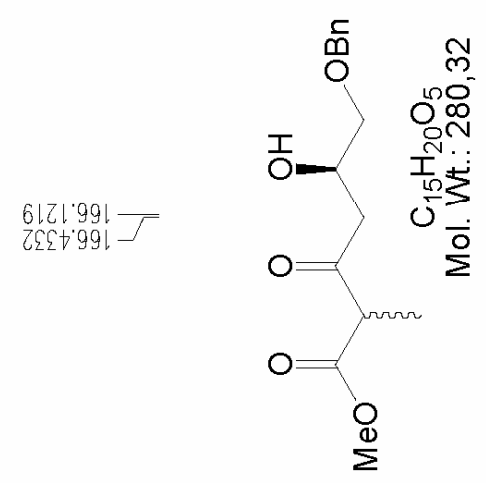

OtZLGOZ -
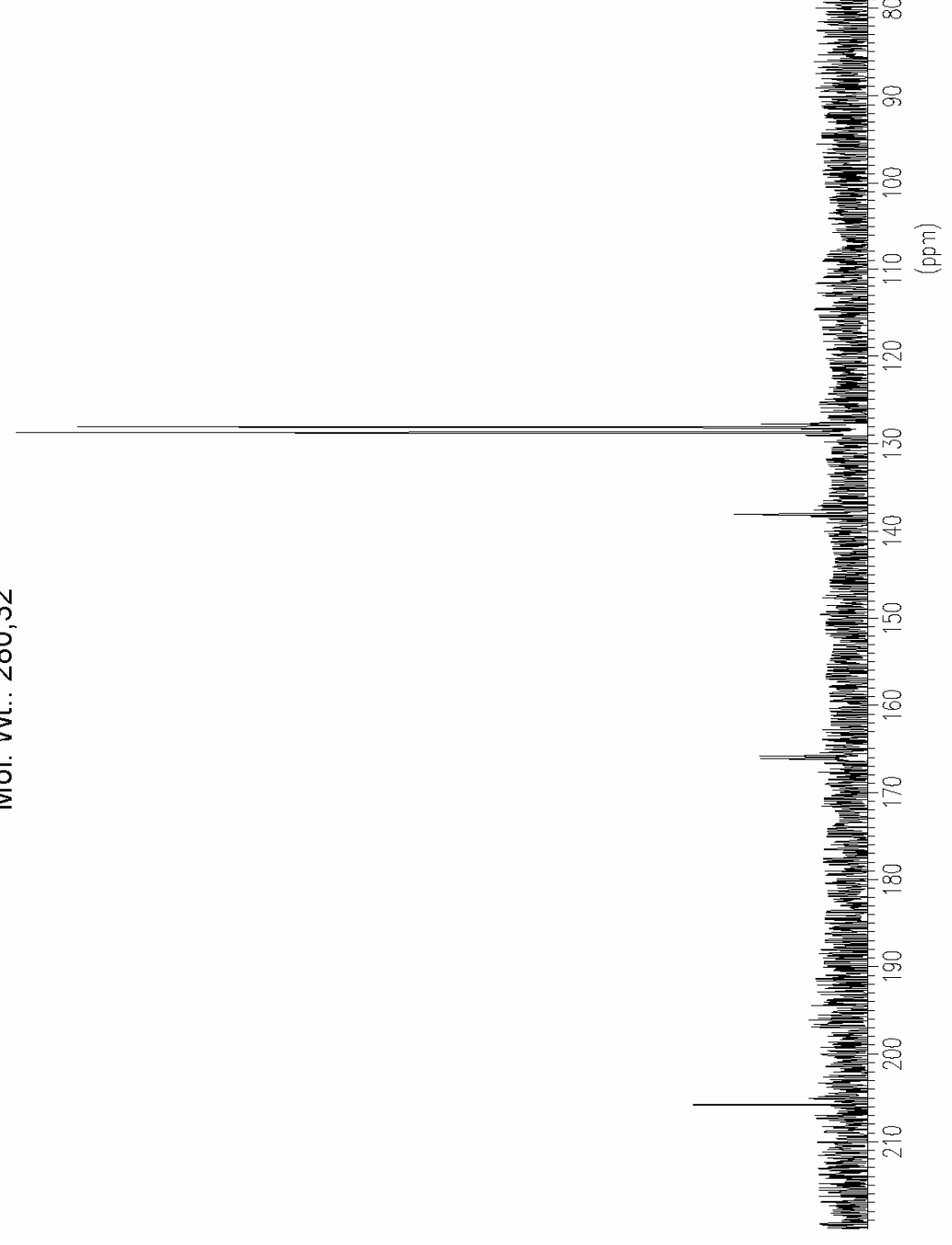


\section{Copy of ${ }^{1} \mathrm{H}$ and ${ }^{13} \mathrm{C}$ NMR spectra of 12}
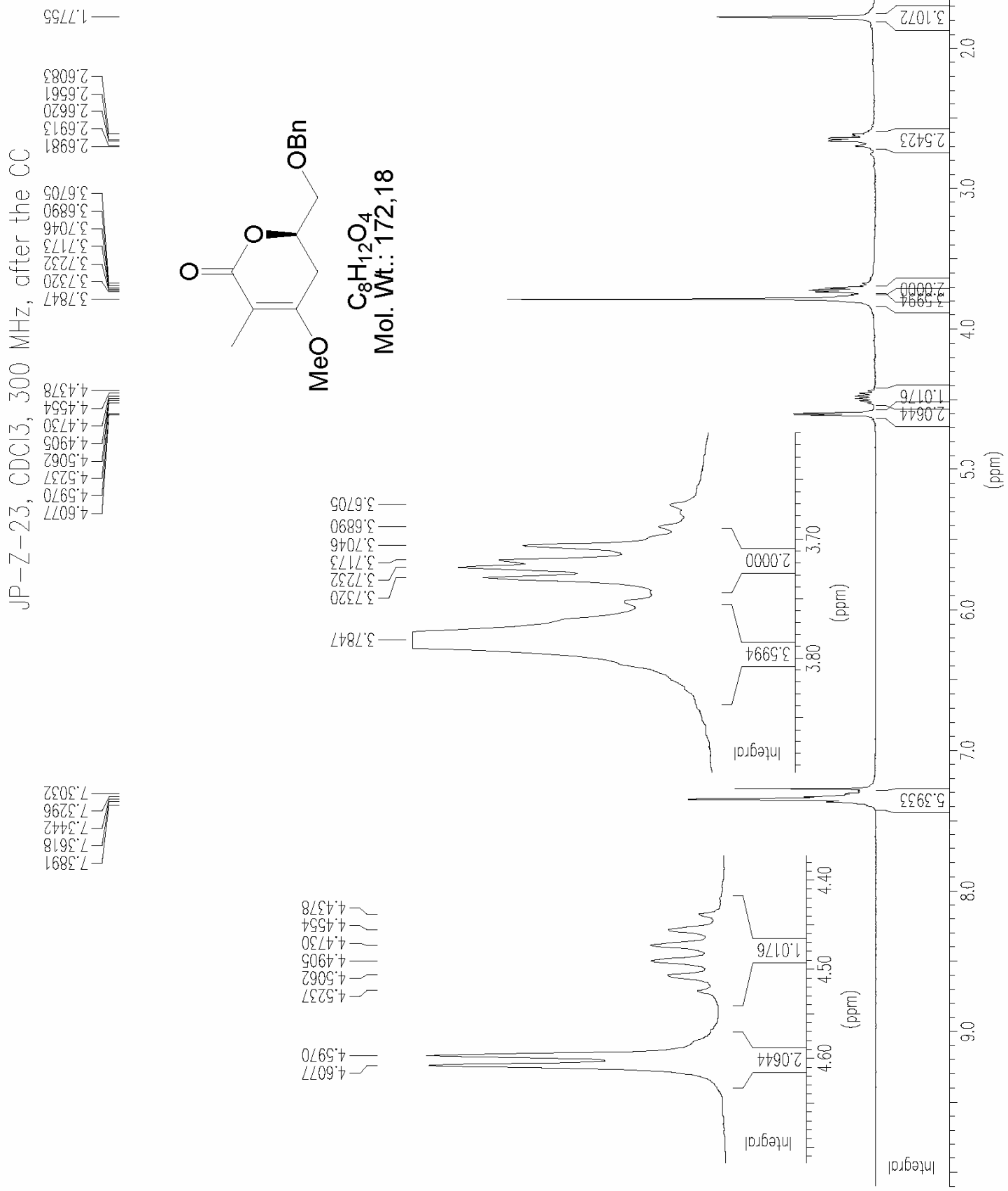

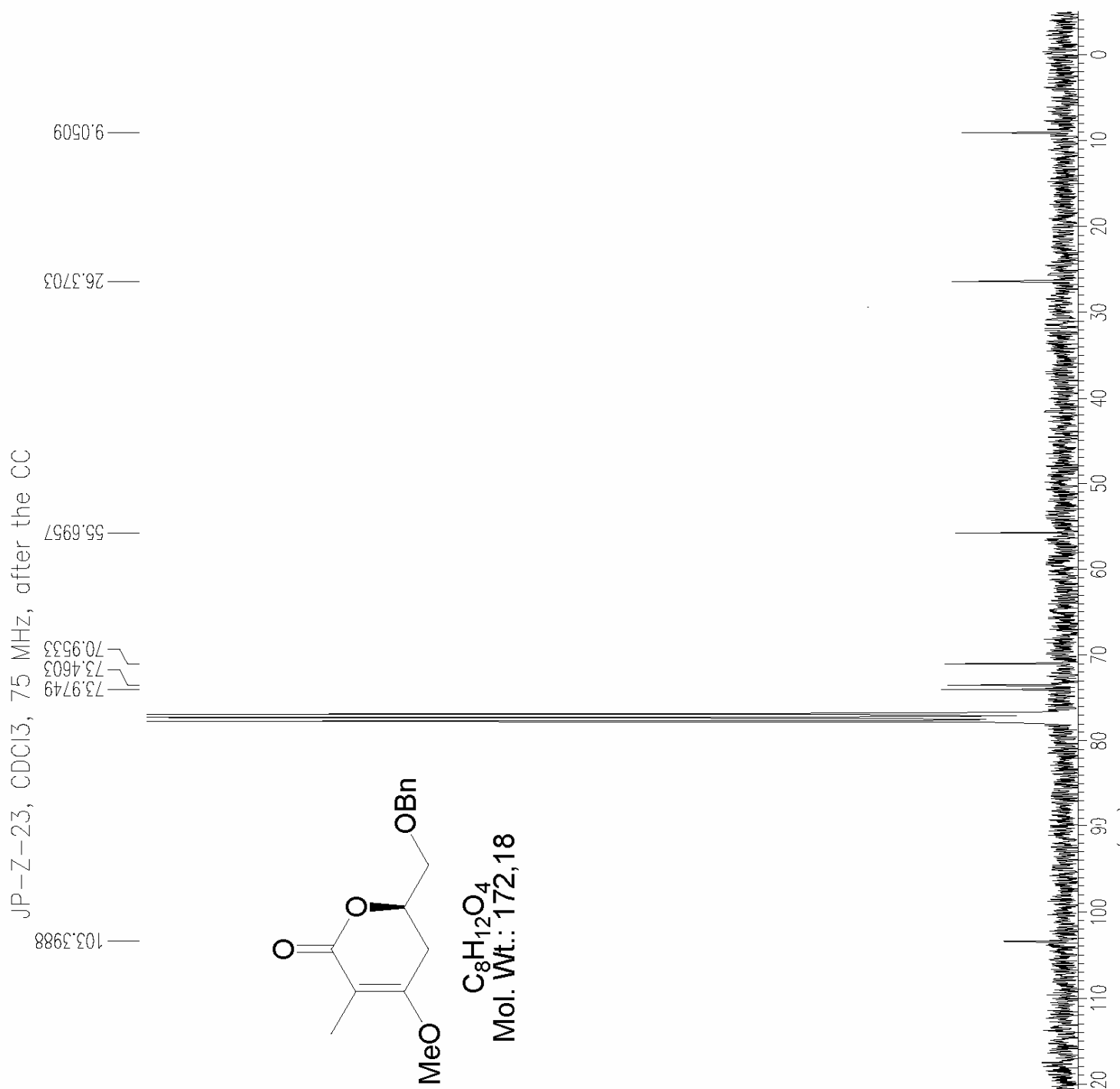

$\varepsilon 150871$
$1871.821-]$
7901.821

$\angle 96 \angle \angle C L$

6999991

$\angle \angle 81.891$.

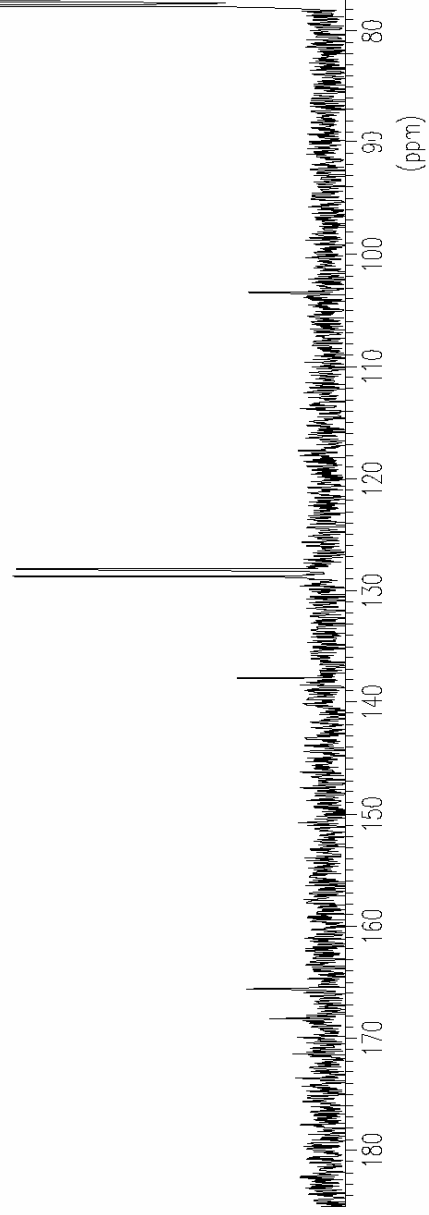




\section{Copy of ${ }^{1} \mathrm{H}$ and ${ }^{13} \mathrm{C}$ NMR spectra of 6}

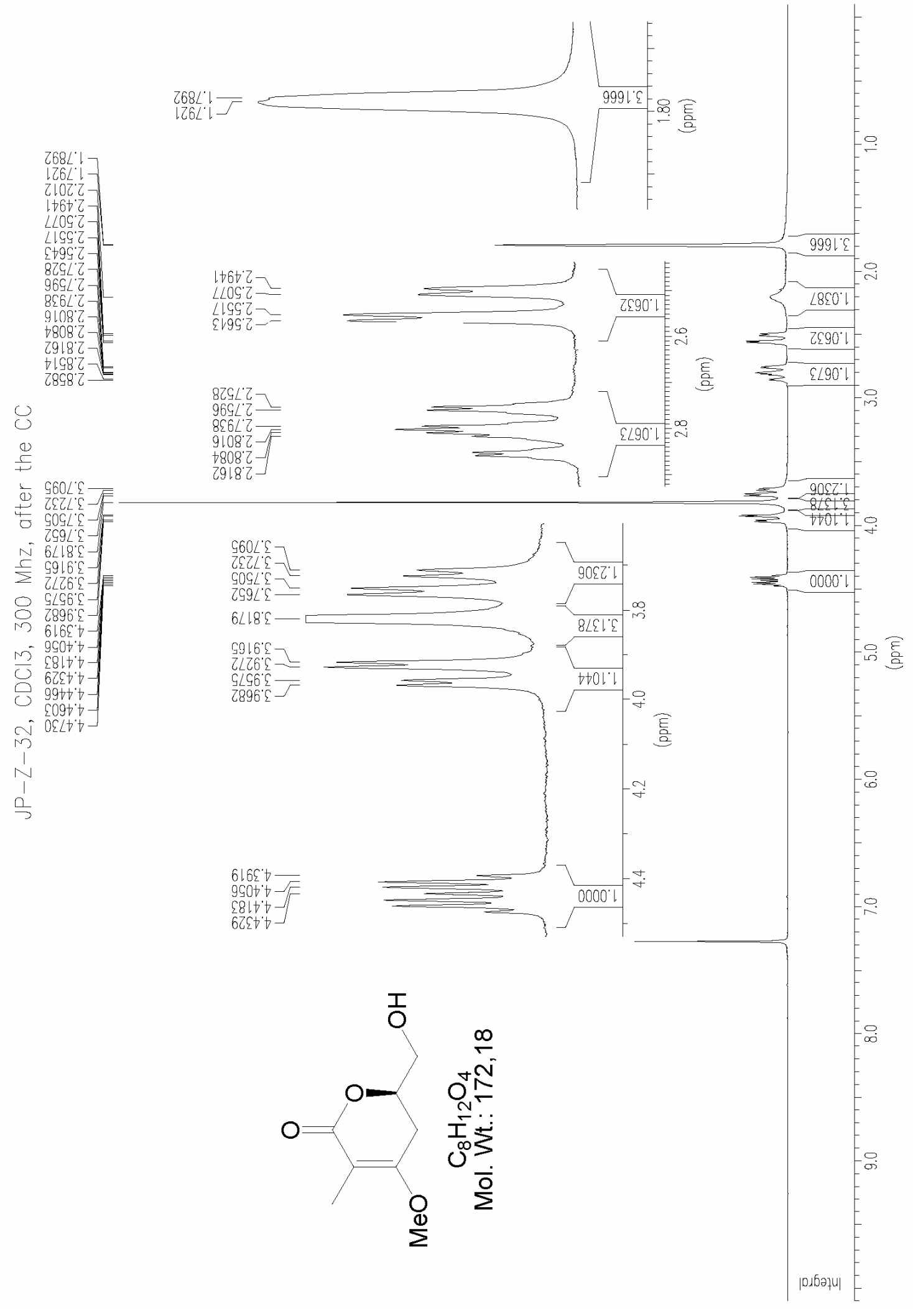


$6090^{\circ} 6$

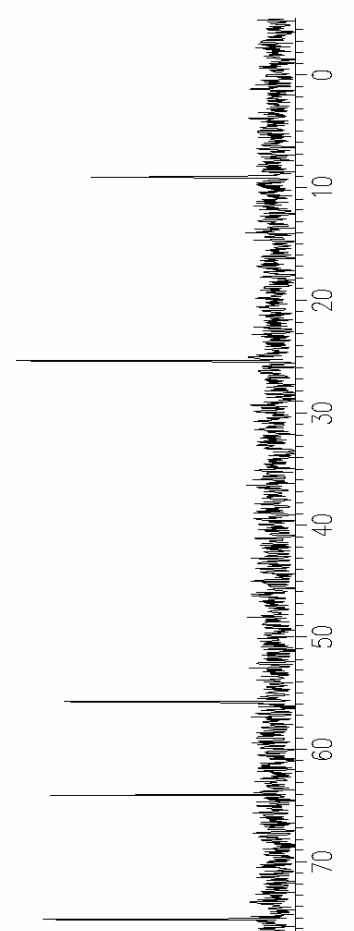

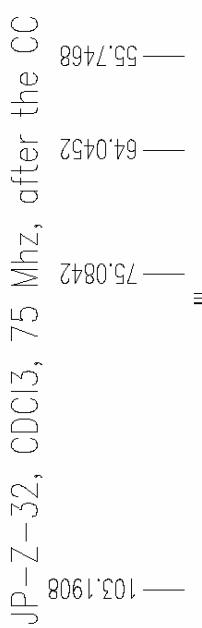

SL6L.991-
$8275.091-$

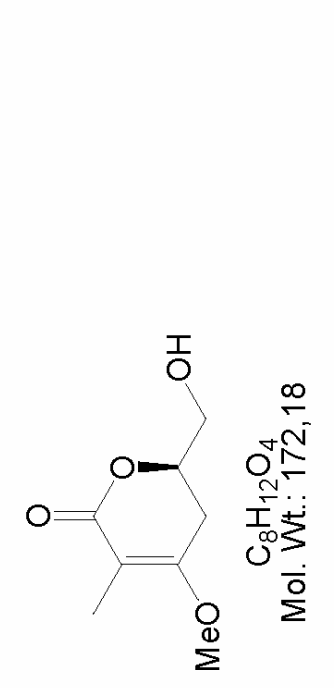




\section{Copy of ${ }^{1} \mathrm{H}$ and ${ }^{13} \mathrm{C}$ NMR spectra of 18}

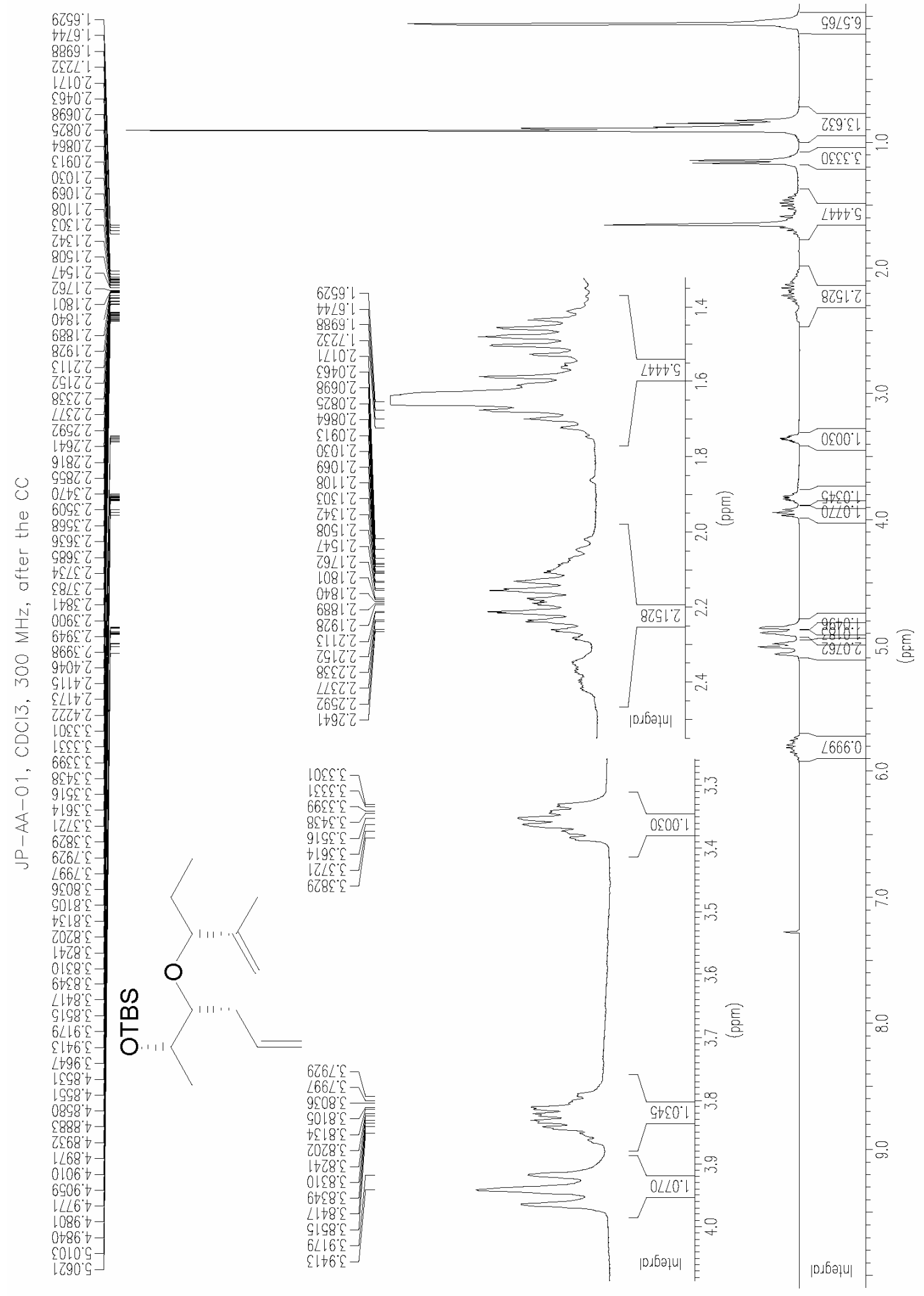


$872 \varphi^{\circ} 7-$

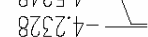

$819701-$

Z12 $2.91-$
$9972.81-5$

EZ8981 -

181.92
+56892

987895

0
0
0
5
+
1
0
+
+
0

$G \angle L \angle O L$

in $\angle 97908$

○ $999998-$

5

5

$\frac{1}{3}$

c886 $\mathrm{Ell}$

6.67911-

$965.97-$
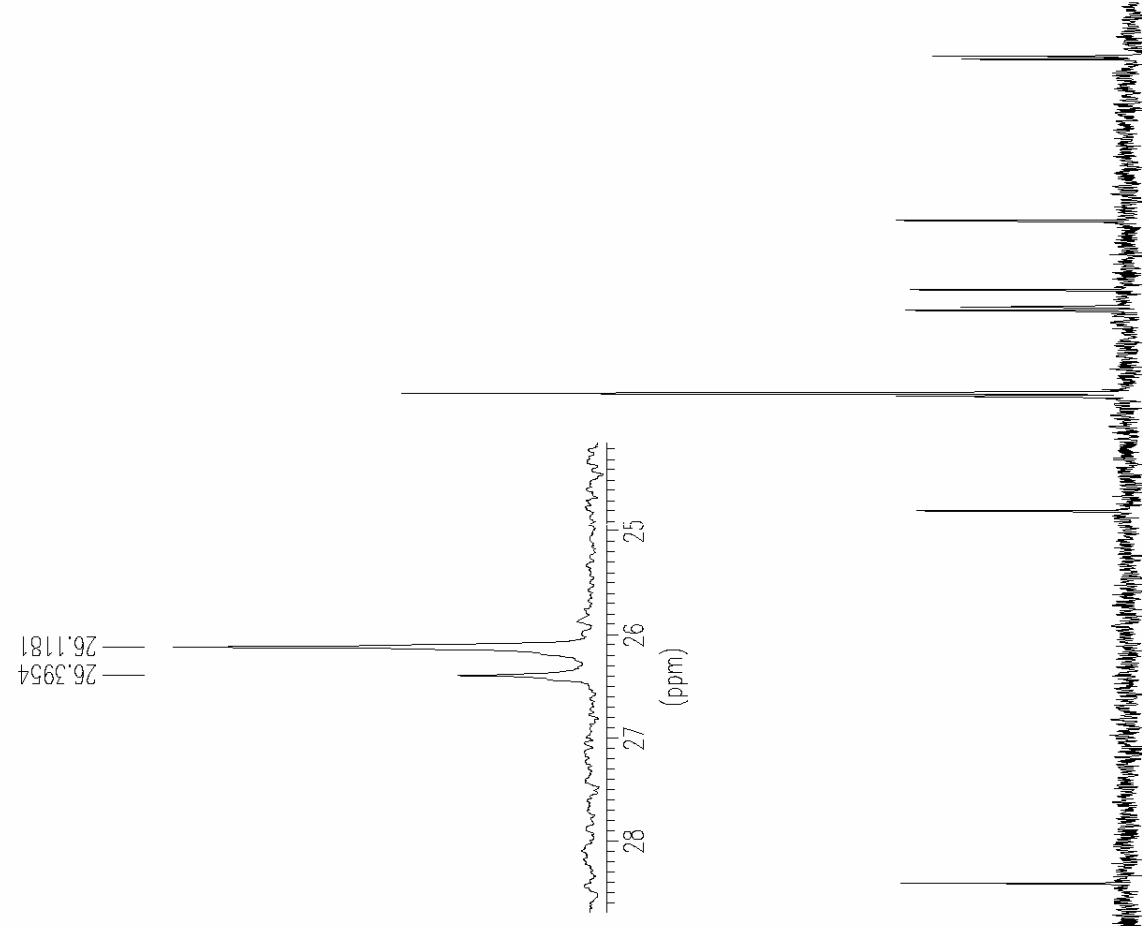

雍
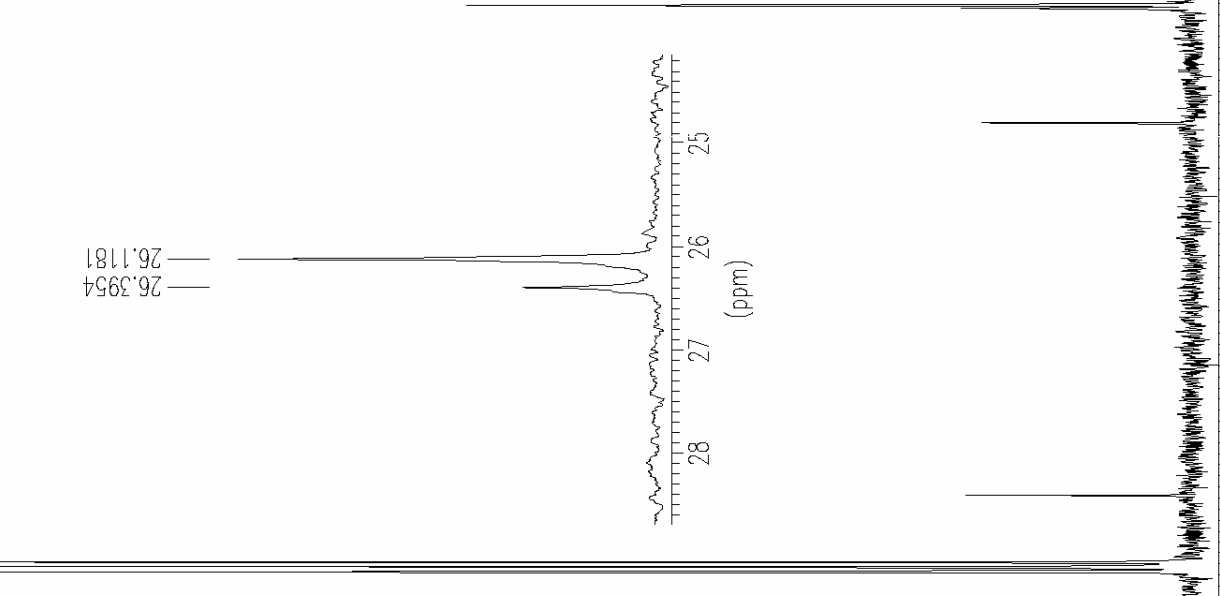

할 $=0$

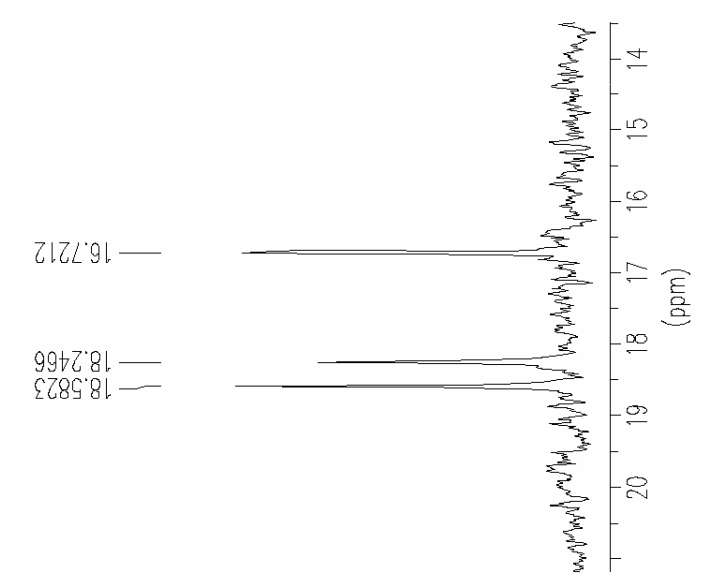

t660'9ع -

$\operatorname{tgctg} t$
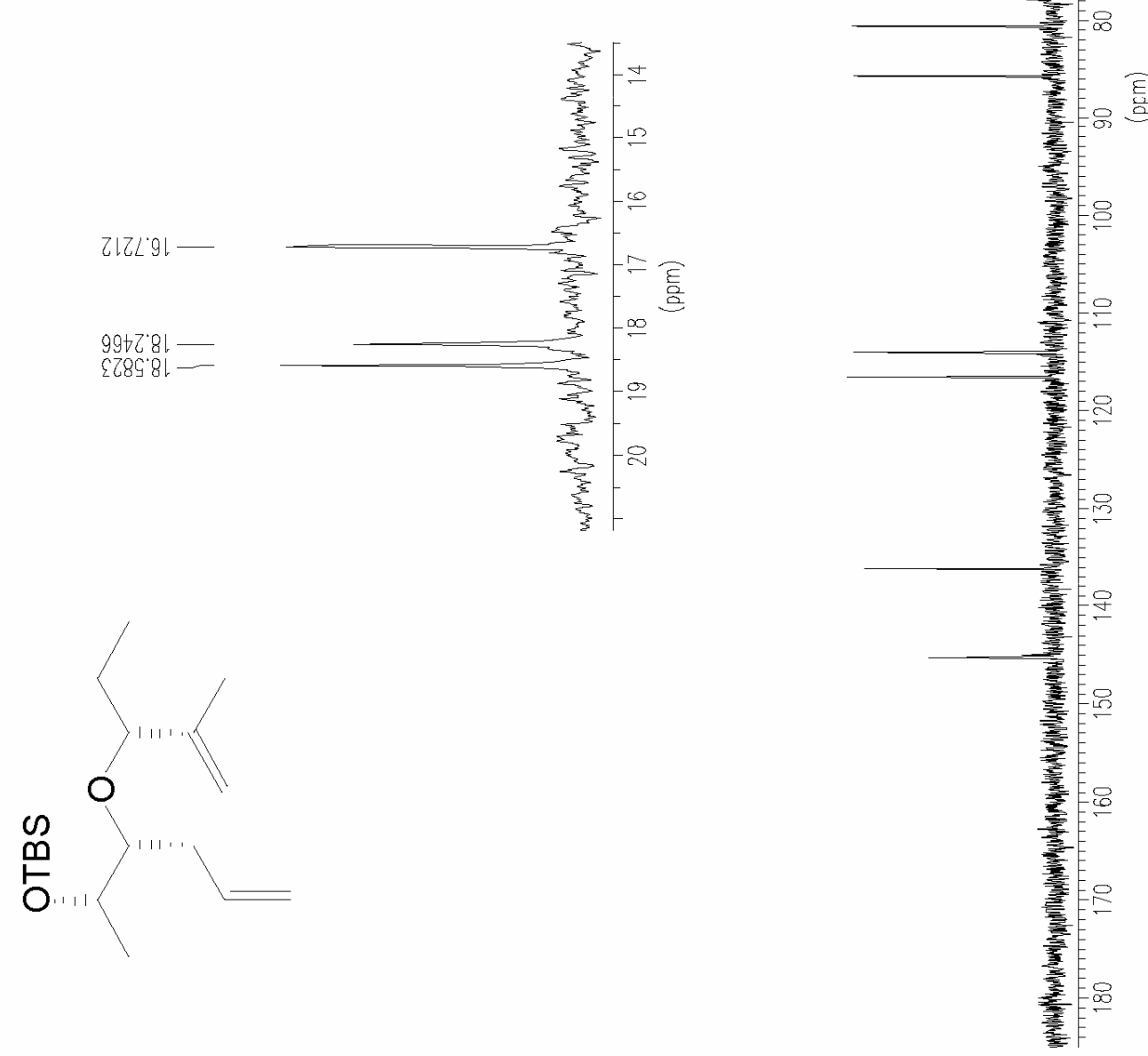


\section{Copy of ${ }^{1} \mathrm{H}$ and ${ }^{13} \mathrm{C}$ NMR spectra of 19}

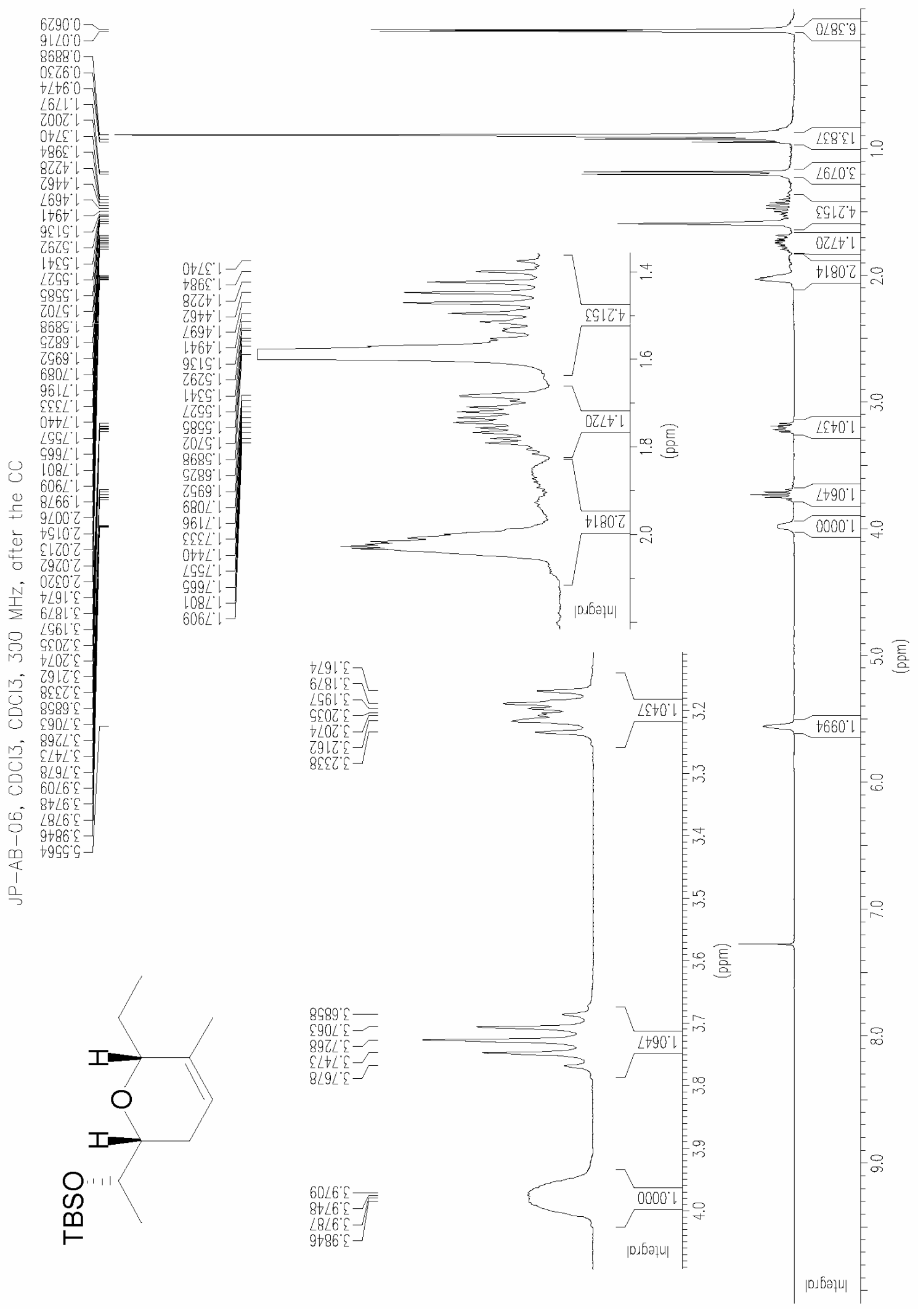




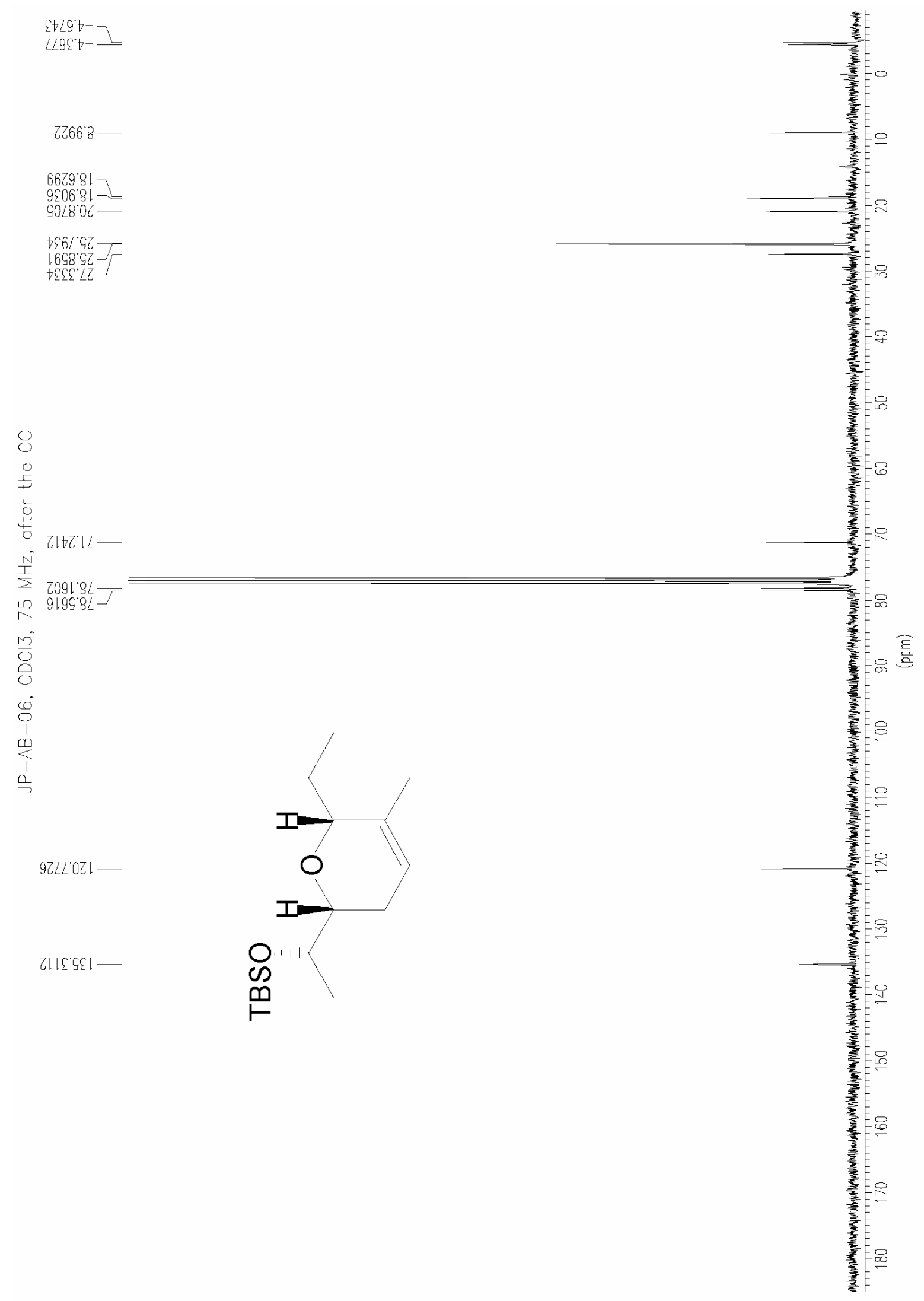

S-13 


\section{Copy of ${ }^{1} \mathrm{H}$ and ${ }^{13} \mathrm{C}$ NMR spectra of 8}

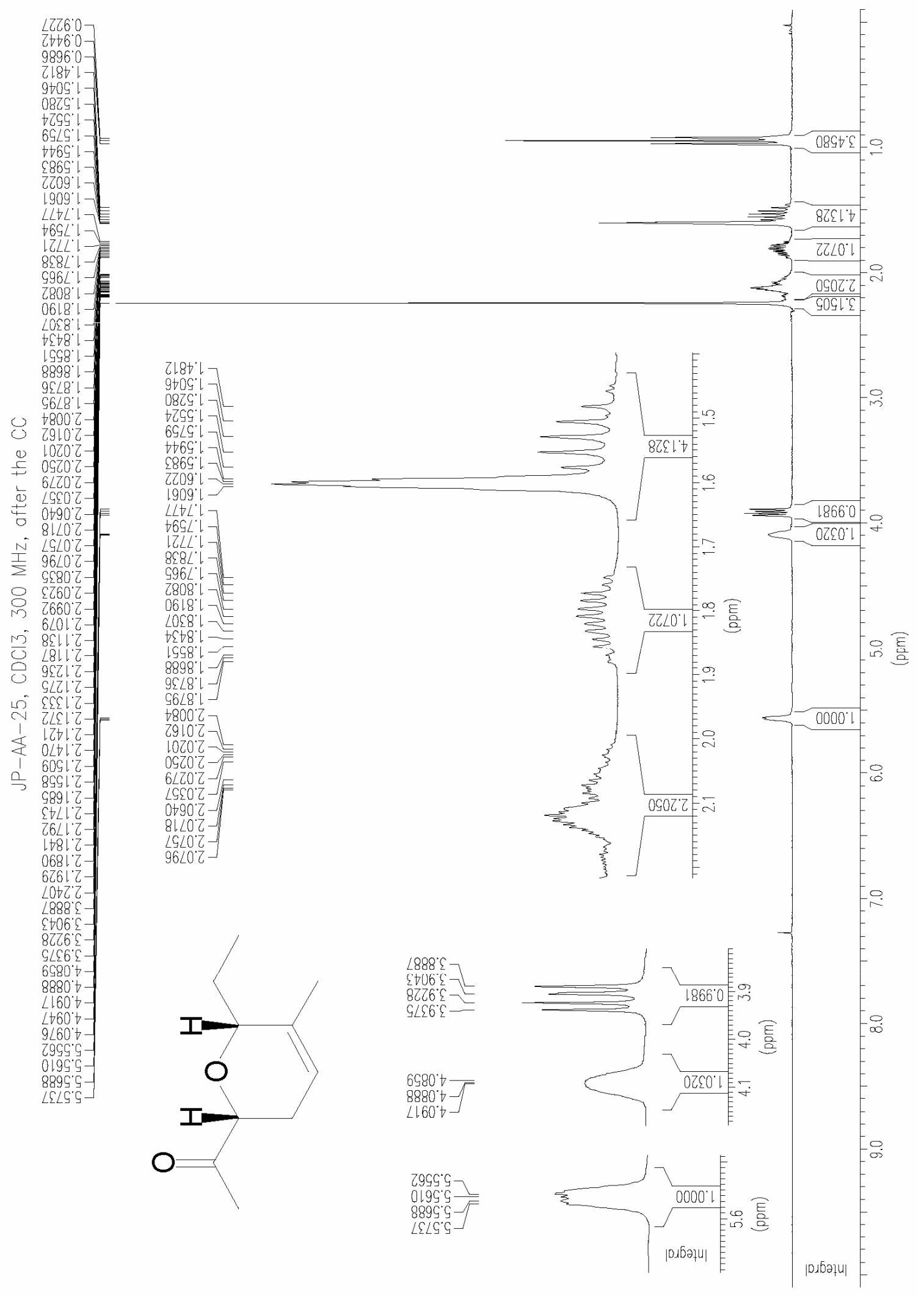


$92298-$

$08 \angle 881$

$825992-$
$890.97-$

$9902 \angle 2=$
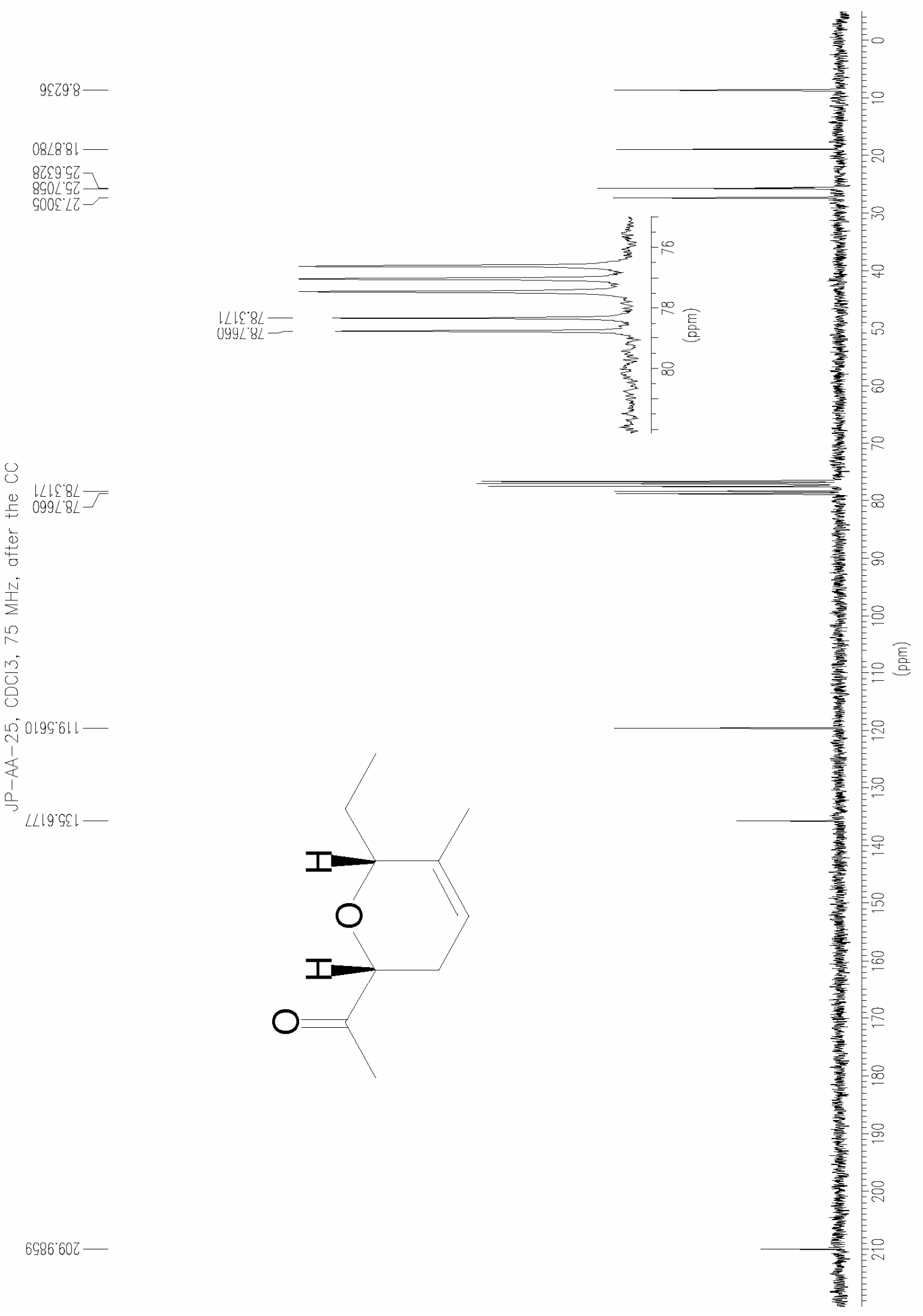

$6986.602-$ 


\section{Copy of ${ }^{1} \mathrm{H}$ and ${ }^{13} \mathrm{C}$ NMR spectra of 25}

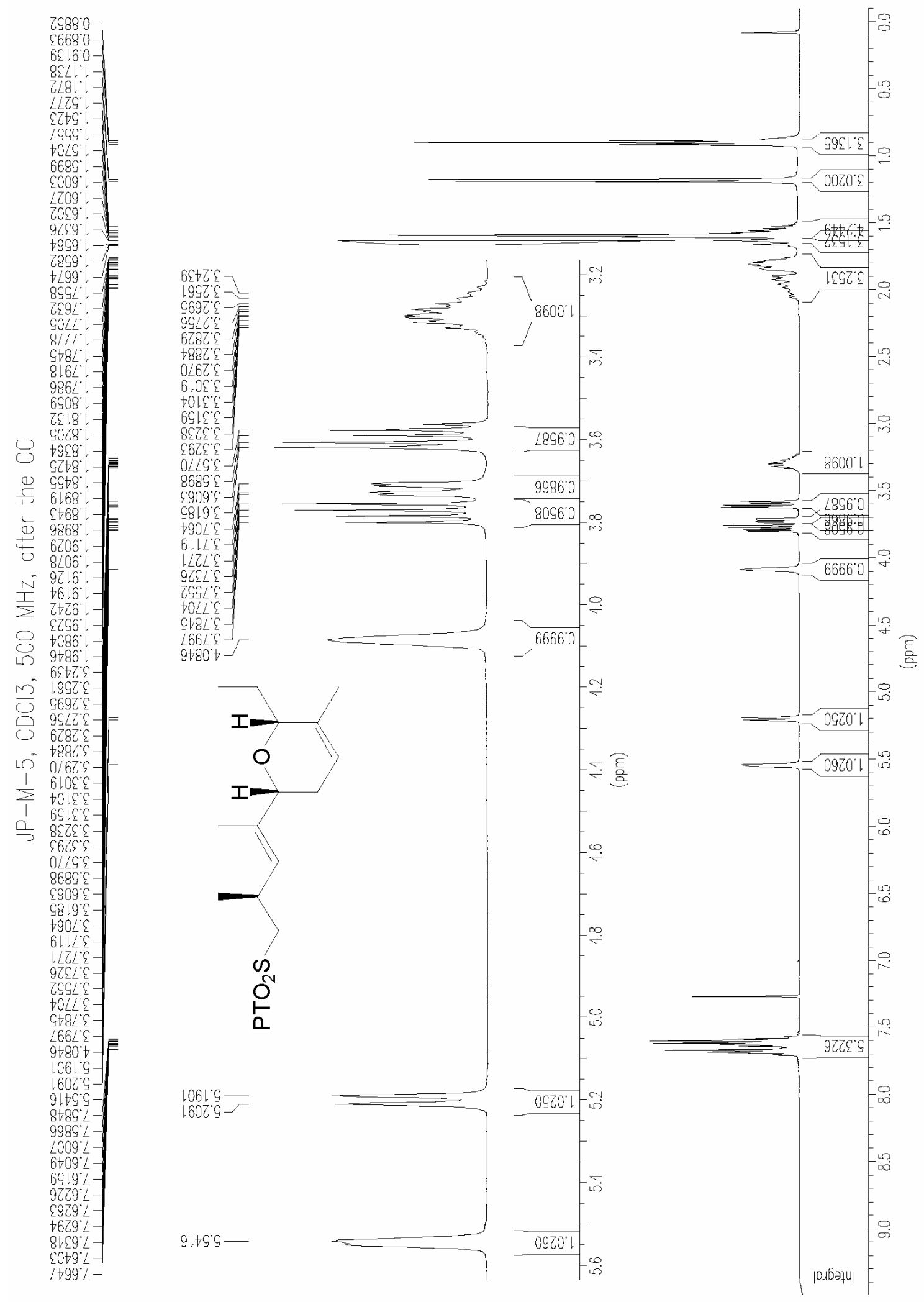




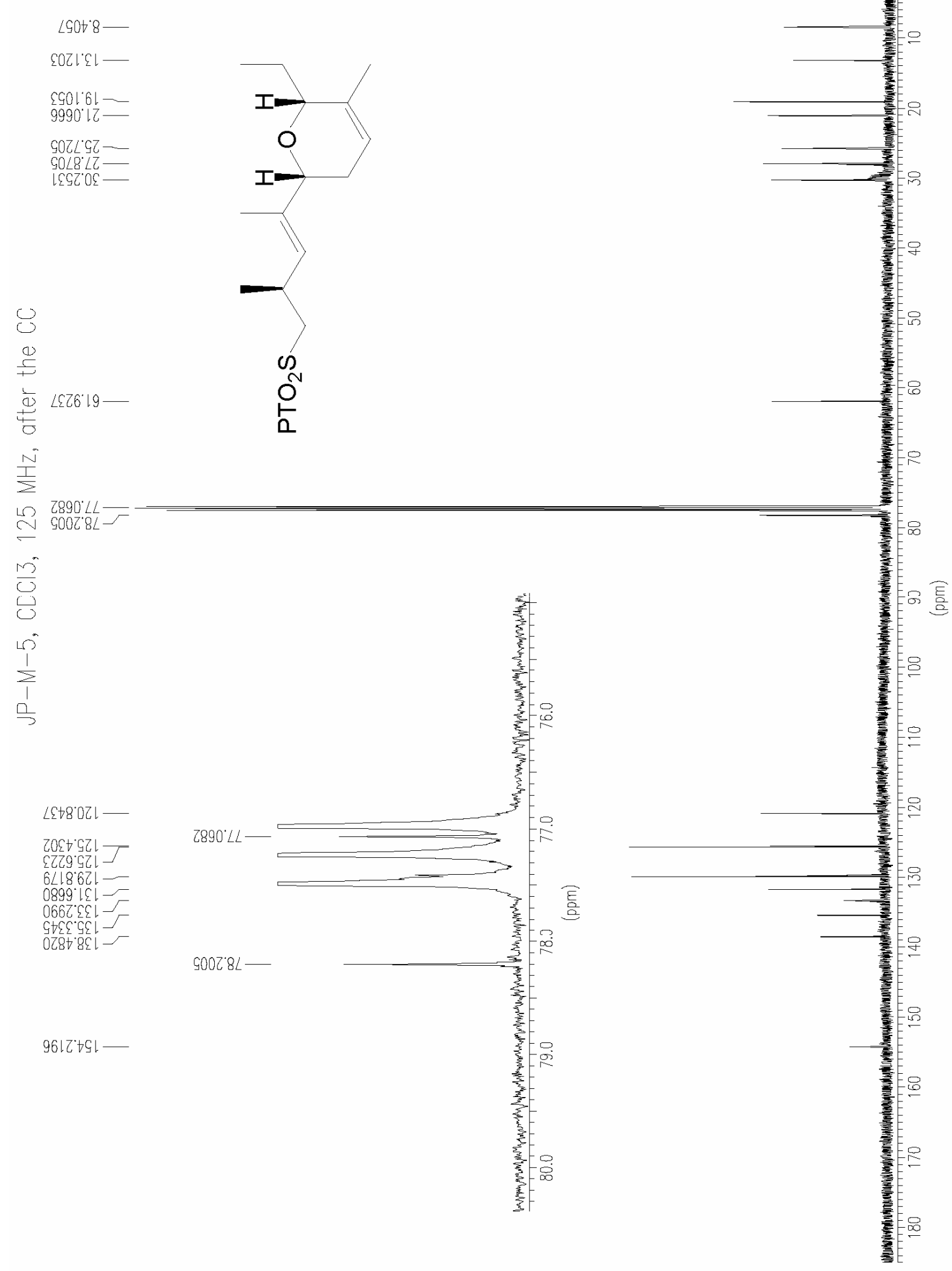




\section{Copy of ${ }^{1} \mathrm{H}$ and ${ }^{13} \mathrm{C}$ NMR spectra of synthetic jerangolid D (2)}

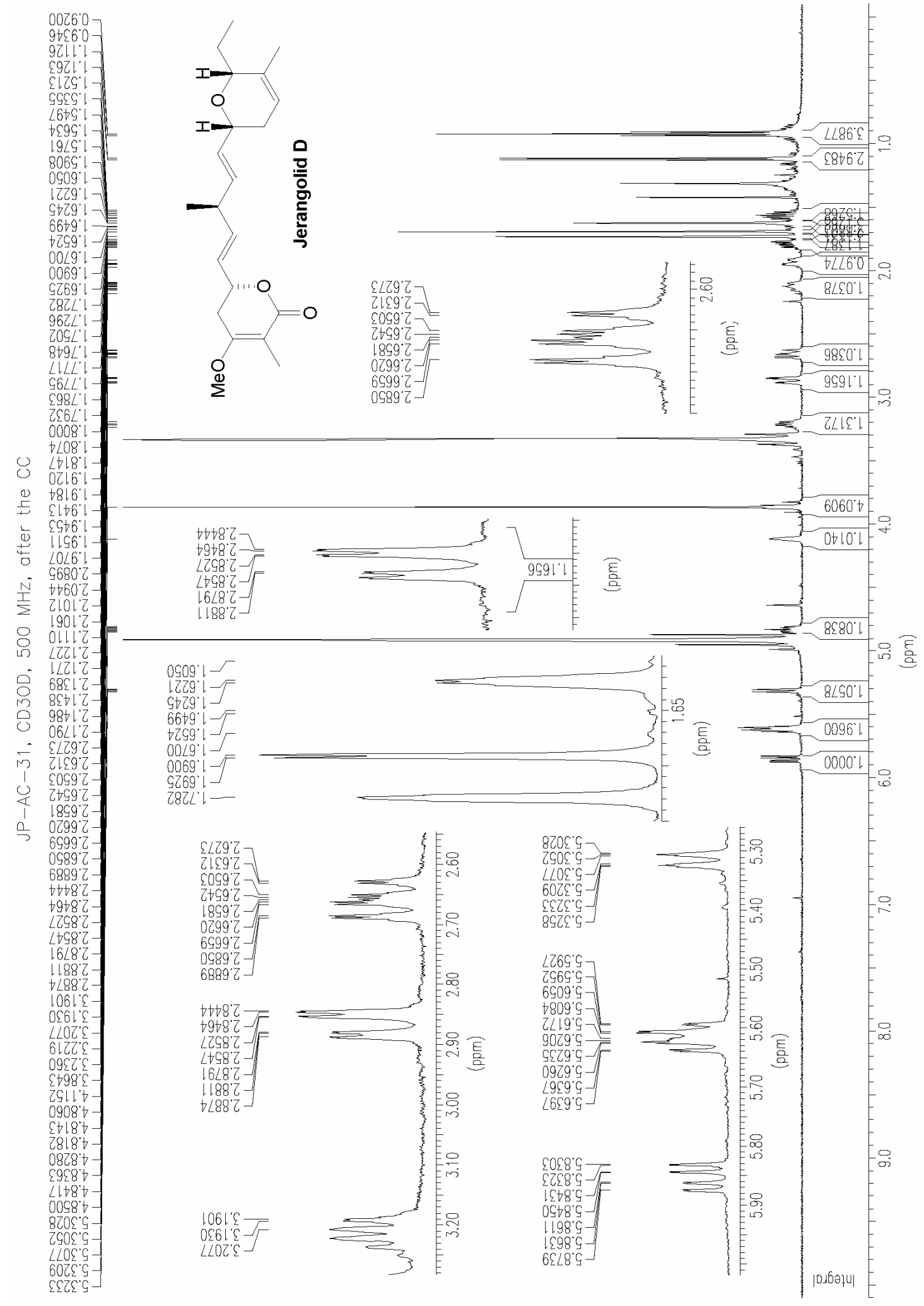




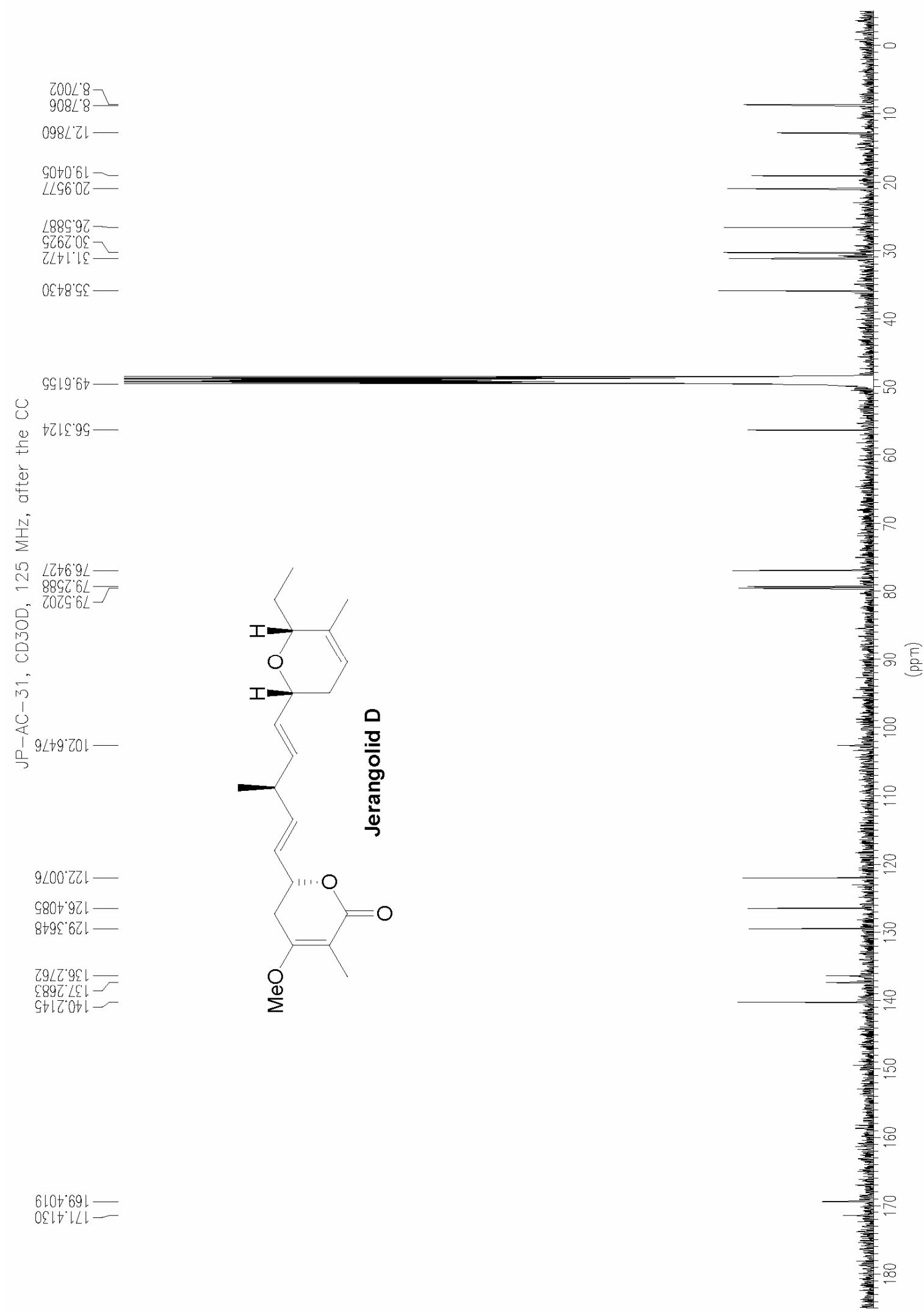


Copy of ${ }^{1} \mathbf{H}$ and ${ }^{13} \mathrm{C}$ NMR spectra of natural jerangolid D (2)

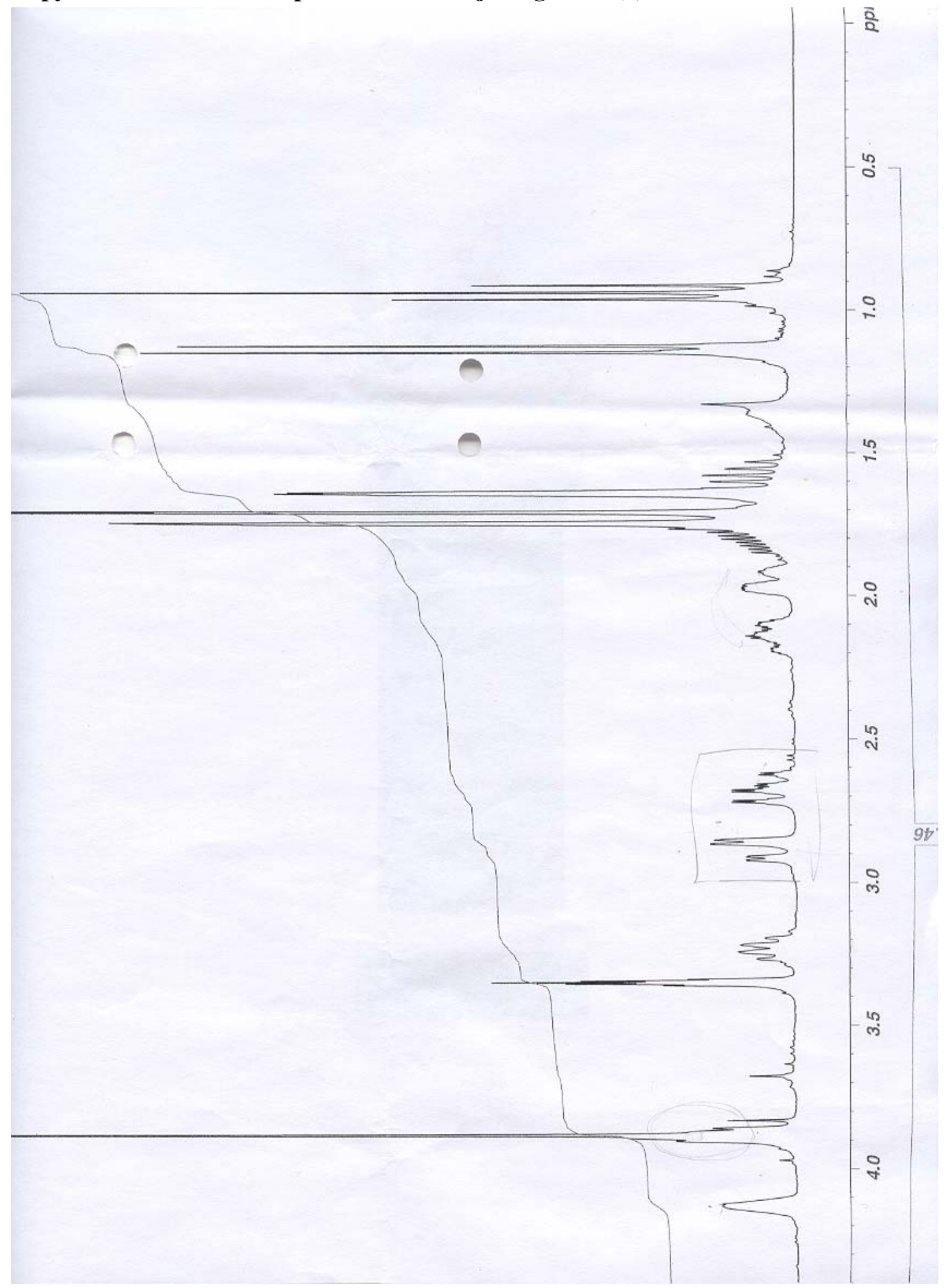




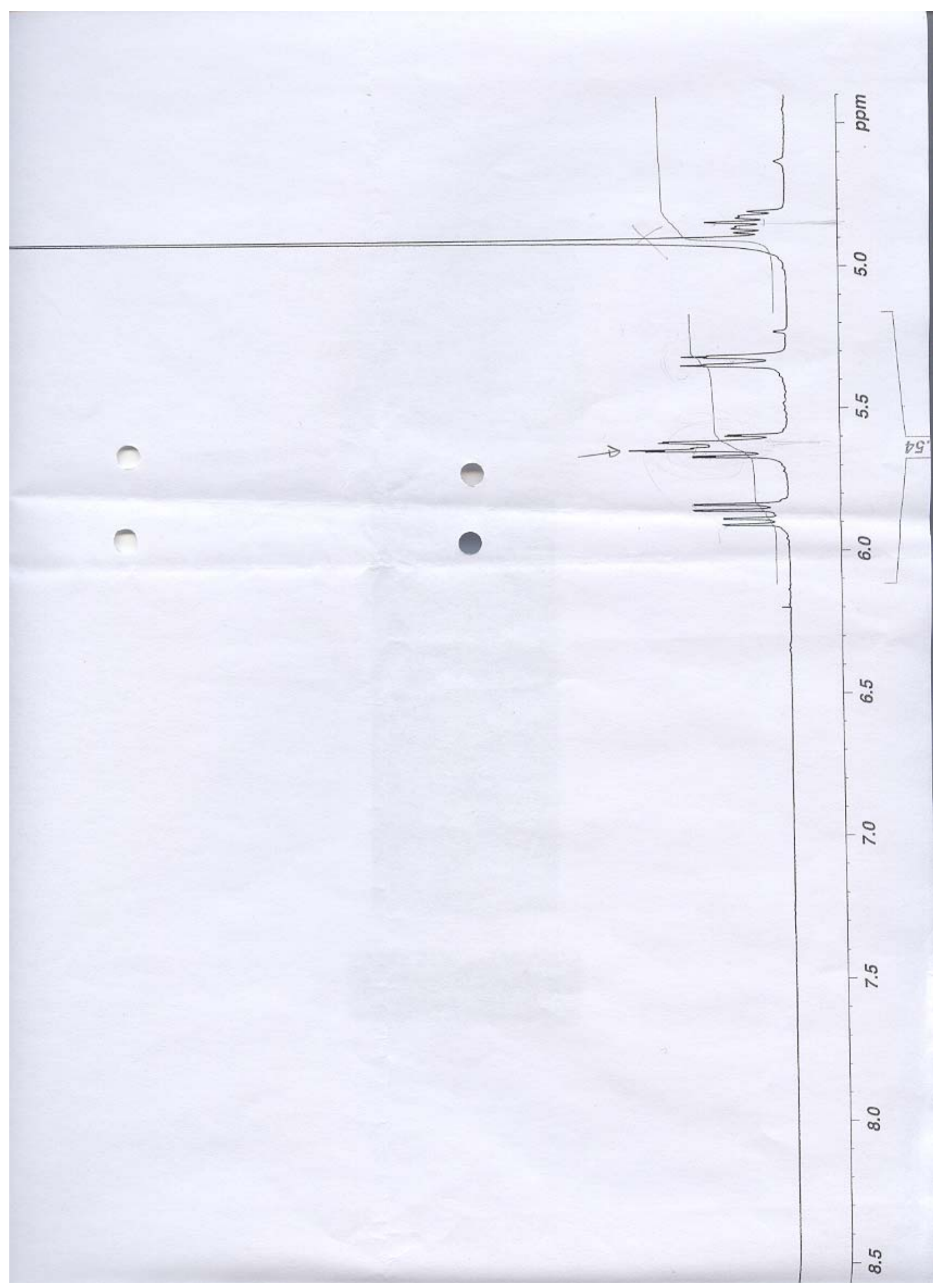




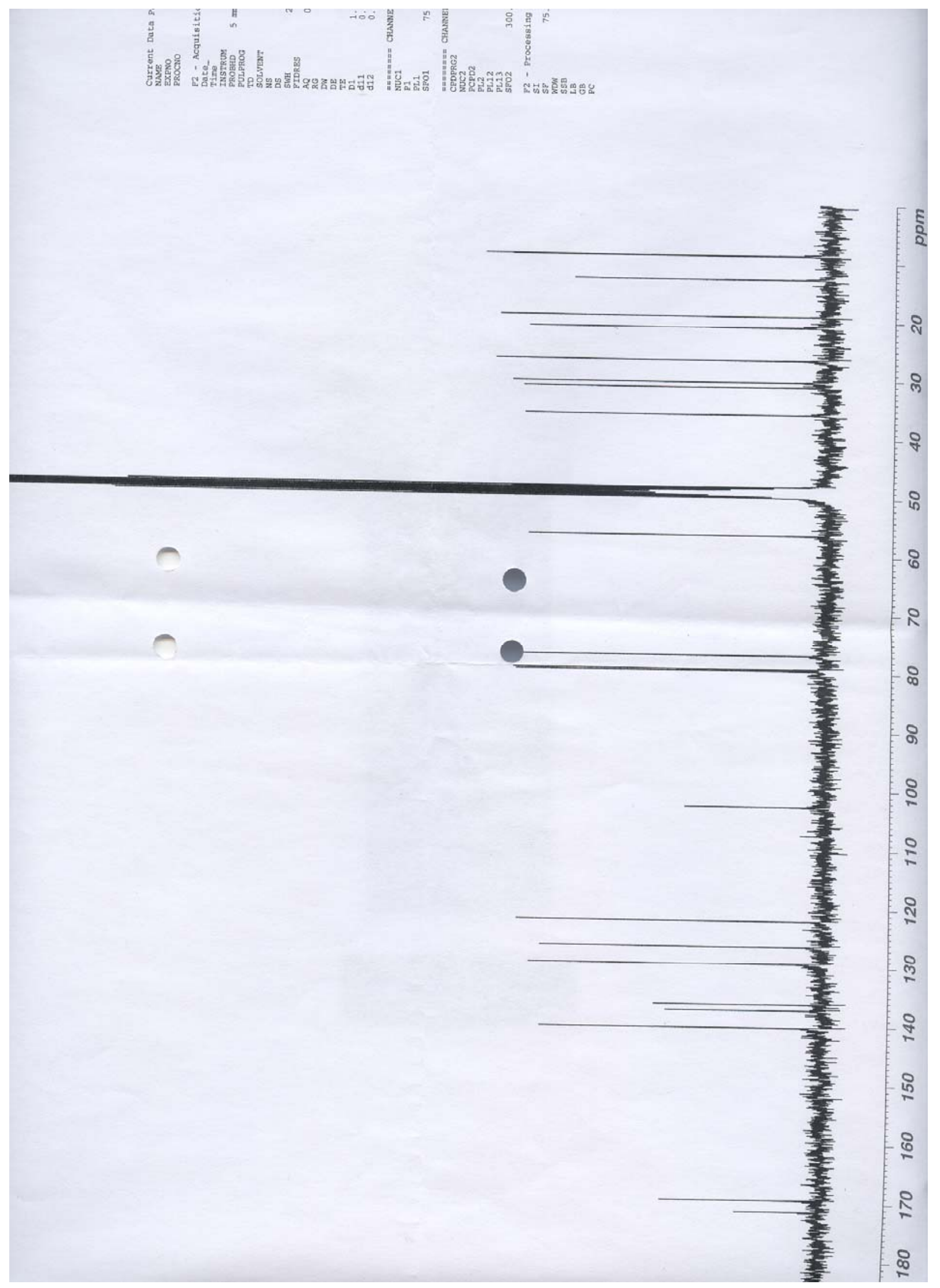


Copy of ${ }^{1} \mathrm{H}$ NMR spectra of commixed natural and synthetic jerangolid D (2)

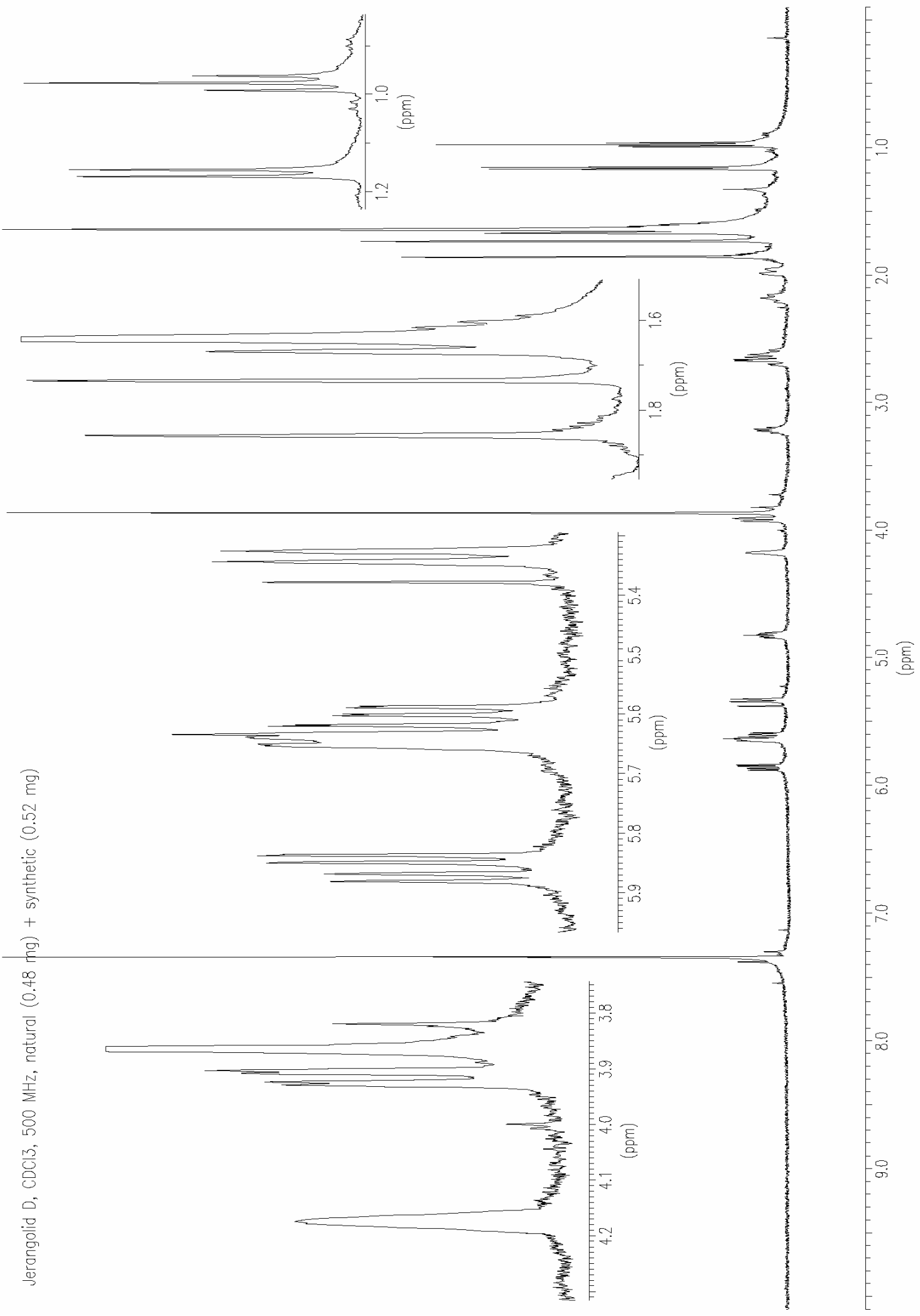

